\title{
The Effect of Gender, Education Level, and Marital Status on Iranian EFL Teachers' Burnout Level
}

\author{
Sina Soltanabadi Farshi (Corresponding author) \\ Department Of English, Tabriz Branch, Islamic Azad University, Tabriz, Iran \\ E-mail: sina.pasha92@gmail.com \\ Fariba Omranzadeh \\ Department Of English, Tabriz Branch, Islamic Azad University, Tabriz, Iran \\ E-mail: faribaomranzadeh@yahoo.com
}

Received: 09-03-2014

doi:10.7575/aiac.ijalel.v.3n.5p.128
Accepted: 09-05-2014

Published: 01-09-2014

\begin{abstract}
The aim of the current study was to survey the effect of gender, education level, and marital status of the EFL teachers on their burnout level in three syndromes of Emotional Exhaustion (EE), Depersonalization (DP), and Personal Accomplishment (PA). The participants of this study were 250 (124male and 126female) English teachers of primary, secondary, high school, and university level. A demographic questionnaire and Maslach Burnout Inventory-Educator Survey (MBI-ES) was employed to collect the data concerning the three dimensions of emotional exhaustion, depersonalization, and reduced personal accomplishment. Descriptive statistics, one sample t-test and one way ANOVA were used in the data analysis process. The findings showed that there is no significant difference between male and female teachers and their burnout level as well as married and single teachers. Moreover, the findings showed that education level of teachers significantly influenced their burnout level in all three syndromes.
\end{abstract}

Keywords: burnout, gender, education level, marital status, EFL teachers

\section{Introduction}

The rapid growth of the importance of learning has made teaching profession one of the world's largest educational enterprises; and therefore, teacher's role cannot be ignored in society. Unfortunately, the realities of classrooms have made teaching a stressful job. Teachers are expected to prepare young adults for a better future while coping with various working conditions, parents, colleagues, the principal and many other psychological and social factors. As a result, many teachers end up having more negative feelings toward themselves, their students, and their profession than they were initially. They start developing feelings of emotional exhaustion and fatigue, negative attitudes towards their students, and loss of feelings of accomplishment in their job. People experiencing these feelings have been described as suffering from 'job burnout' (Maslach\& Jackson, 1981; Maslach\& Goldberg, 1998; Maslach, Schaufeli\&Leiter, 2001). The main purpose of the present research was to determine the extent to which teacher burnout is related to gender, education level, and marital status. The three research questions of this paper were as follows:

1) Does gender affect the level of burnout among EFL teachers?

2)Does level of education affect the level of burnout among EFL teachers?

3) Does marital status affect the level of burnout among EFL teachers?

Much of the research in the area of burnout can be traced to Herbert Freudenberger, a psychologist practicing in New York during the 1960's and 70's. Freudenberger employed the term 'burnout' to describe the effects of overwork, exhaustion and frustration that he experienced while operating a free clinic for drug users and indigent persons. Freudenberger first introduced this concept in 1974, and he defined the problem as one of chronic exhaustions and frustrations resulting from continued devotion to a goal or a principle that had failed to produce a corresponding reward. It was defined as wearing down or wearing out of energy (Freudenberger\& North, 1985). Some other views can be added to Freudenberger's definition to give an exact meaning to the concept of burnout. According to Pines and Aronson (1988), burnout is formally clarified and subjectively experienced as a state of physical, emotional, and mental exhaustion which is caused by long-term involvement in situation that are emotionally demanding. The term "burnout" originated during the 1960's as a description of the effect of drug abuse on an individual (Capel, 1993; Landeche, 2009). In addition, Maslach is one of the pioneers in the study of teacher burnout. Maslach (1981) defined burnout as a syndrome that characterized with disturbing physical and emotional characteristics. Further, she pointed out burnout as a condition that is characterized by emotional exhaustion, depersonalization and loss of a sense of personal accomplishment. This condition is developed primarily in individuals who work in human services; or occupations such as education, social work, police and emergency services. Burnout is manifested in the following ways: work overload, 
lack of control over one's work environment, lack of community among teachers in the school, lack of fairness in work assignments and uneven distribution or absence of rewards (Maslach\& Jackson, 1981). According to Sedgwick (1998), burnout is formally clarified and subjectively experienced as a state of physical, emotional, and personal causes. Emotional Exhaustion (EE) shows the feelings of over extension and exhaustion which is caused by daily work pressures and conflicts with the colleagues. Depersonalization (DP) indicates the development of negative attitude and impersonal responses towards the people with whom one works. Meanwhile, Personal accomplishment (PA) refers to the sense of personal achievement that is accompanied by self-esteem. It is inversely related with burnout.

Several studies have been conducted to identify the causes associated with burnout among teachers. For instance, studies carried out in Australia, Canada, Israel, New Zealand, the Netherlands, the United Kingdom, and the United States have found similar causes of burnout in professional educators (Coulter \& Abney, 2009). There are a number of studies dealing with the burnout issue which have included many variables that may affect teachers' level of burnout such as age, gender, marital status, as well as level of education, teaching level, teaching experience, and job satisfaction. The most common variables for these studies are gender, marital status, teaching experiences, as well as professional and religious backgrounds. The findings of Maslach, Jackson, and Leiter (1996) on service professionals including teachers indicated that female staff had higher emotional exhaustion than their male colleagues. Similarity, Lau, Yuen, and Chan (2005) explored the relationship between teachers' demographic variables and burnout by using the MBI questionnaire among 1797 participants from 45 secondary schools in Hong Kong. Gender differences were found in all three burnout syndromes. Al-Qaryoti and Al-Khateeb (2006) carried out a study among 447 teachers (129 males, 318 females) in Jordon and revealed that there was no significant difference between the teachers in term of their burnout level according to the gender. Greenglass, Pantony, and Burke (1988) in a vast research on gender-related burnout of the teachers, reported a higher rate of burnout among women than men. This was inconsistent with the results reported by Salami (2011), and Toker (2011).

Bulks of research have been done by several researchers to find out the effect of marital status on burnout level of teachers. Number of studies found that single teachers are in higher levels of burnout than married teachers (Jackson, Schwab, \& Schuler, 1986). However, the opposite has been also found; according to Bayram, Gursakal, and Bilgel (2010), marital status had no significant effect on burnout level of teachers. Few researches have been done to determine the effect of educational level of teachers on their level of burnout. In a research conducted by F. Sezer (2012), he has reported that burnout level is high among high-educated teachers compared to low-educated teachers.

Since burned out teachers affect themselves, students, and educational system negatively (Hughes, 2001, as cited in Asghari, 2009), it is important to find its reasons and measure their burnout level as accurately as possible. The works in domain of teacher burnout identify its causes among teachers; and when the causes are clear, educational managers can find ways to prevent teachers from being burned out. Moreover, since few works have been done to determine the relative effects of demographic variables on teacher burnout in Iran, and especially in northeast, the aim of this research was to determine the effects of three demographic variables (gender, education level, and marital status) on burnout level of EFL teachers in this area (northeast of Iran).

\section{Method}

\subsection{Design}

This work has been conducted in a survey mode. In this piece of research, a quasi-experimental quantitative type of method has been used due to several reasons. It was more economical and timesaving in this field of study. Another advantage is that the results would show the exact linkage between the independent variables (gender, education level, and marital status) and dependent one (Burnout among EFL teachers).

\subsection{Participants}

Participants of current study were a random sample of 250 male and female, single and married EFL teachers at different levels of education, in different schools and private English language institutes in northwest of Iran, whose district of teaching was urban. The participants were 124 males and 126 females, of whom a total number of 179 were married and the rest were single in three educational levels of Bachelor $(\mathrm{N}=120)$, Master $(\mathrm{n}=91)$, and Ph.D. $(\mathrm{N}=39)$. The participants were all EFL teachers of primary, secondary, high school, and university level.

\subsection{Instruments}

In the current research, two different types of questionnaires have been used: A Demographic Questionnaire and the Maslach Burnout Inventory- Educator Survey (MBI-ES). The Demographic Questionnaire has been utilized including thirteen items through which some information such as age, gender, level of education, marital status, number of children, teaching experience have been gathered.

In addition, MBI-Educators Survey has been used which has been developed by Maslach (1986). It consists of twentytwo questions about three different aspects of teacher burnout: Emotional exhaustion (EE), Depersonalization (DP), Personal accomplishment (PA). The frequency scale ranged from zero (never), to six (every day). Emotional exhaustion itself consists of nine questions, which measure the emotional side of teacher burnout, and shows the feeling of teachers toward their job. (e.g., I feel emotionally drained of my work). Depersonalization includes five questions through which, they mention their view toward their students and other people around them. (e.g., I have become more callous toward people since I have taken this job). Finally, personal accomplishment part has eight questions, which are related 
to the teachers' feeling toward their own performance in their job. (e.g., I have accomplished many worthwhile things at this job).

\subsection{Data Collection Procedure}

In this work, the required data were collected among 250 teachers in several schools, universities, and foreign language institutes in northwest of Iran. To collect the needed data, the researchers referred to some language institutes, schools, and universities and asked the teachers to fill out the questionnaires; and to consider the time and cost, some questionnaires were sent by e-mail to some teachers who were not in access. From the overall 405 sent and distributed questionnaires, 250 were filled and returned.

\section{Results}

Since the main purpose of the study was to determine whether there was any statistically significant difference between gender, education level, and marital status and the overall burnout level among English teachers, descriptive statistics, $t$ test and Analysis of Variance (ANOVA) were performed on the collected data. Gender, education level, and marital status were regarded as independent variables, while the burnout level of the teachers was considered as dependent variable. The items were measured on a 7-point Likert scale, ranging from never to every day. The range of scores for the levels of burnout are the high $(\mathrm{EE}=27$ or over; $\mathrm{DP}=13$ or over; $\mathrm{PA}=0-31)$, moderate $(\mathrm{EE}=17-26 ; \mathrm{DP}=7-12 ; \mathrm{PA}$ $=32-38)$, and low $(\mathrm{EE}=0-16 ; \mathrm{DP}=0-6 ; \mathrm{PA}=39$ or over) according to Maslach, Jackson, and Leiter (1996). Based on Maslach et al. (1996), higher scores in EE and DP represent higher degrees of experienced burnout. In contrast, lower scores in PA demonstrate higher degrees of experienced burnout.

In order to find out the burnout level of the participants, the means and standard deviations of the three burnout syndromes were calculated. The mean scores for emotional exhaustion, depersonalization and personal accomplishment were found to be 20.8 ( $\mathrm{SD}=12.19), 6.96(\mathrm{SD}=8.68)$, and $35.72(\mathrm{SD}=8.78)$ respectively. According to the findings indicated in table 1, participants were at moderate level of burnout due to the ranges introduced above.

Table 1. Statistics and one-sample t-test for the burnout dimension

sig. $\quad 95 \%$ Confidence Interval

\begin{tabular}{|c|c|c|c|c|c|c|c|c|}
\hline \multirow[b]{2}{*}{ Burnout } & \multirow[b]{2}{*}{$\mathrm{N}$} & \multirow[b]{2}{*}{ Mean } & \multirow[b]{2}{*}{$\mathrm{SD}$} & \multirow[b]{2}{*}{$\mathrm{T}$} & \multirow{2}{*}{\multicolumn{2}{|c|}{ Df }} & & \\
\hline & & & & & & & Lower & Upper \\
\hline Emotional Exhaustion & 250 & 20.8 & 12.19 & 26.99 & 249 & .000 & 19.28 & 22.32 \\
\hline Depersonalization & 250 & 6.96 & 8.68 & 12.67 & 249 & .000 & 5.88 & 8.04 \\
\hline Personal Accomplishment & 250 & 35.72 & 8.78 & 64.29 & 249 & .000 & 34.62 & 36.81 \\
\hline
\end{tabular}

In order to determine how well gender, education level, and marital status affect emotional exhaustion, depersonalization and personal accomplishment among EFL teachers, the one-sample t-test method was employed. The results of the analysis are presented in Table 2 below:

Table 2. Means and standard deviations for three syndromes of burnout according to gender, education level, and marital status

\begin{tabular}{|c|c|c|}
\hline Emotional Exhaustion & Depersonalization & Personal Accomplishment \\
\hline
\end{tabular}

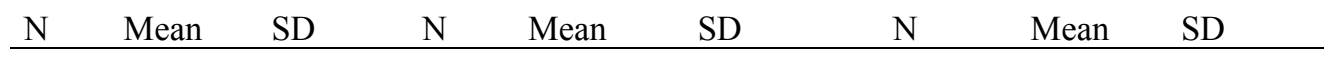

\begin{tabular}{lccccccccc} 
Male & 124 & 19.90 & 10.74 & 124 & 6.37 & 7.81 & 124 & 35.96 & 8.90 \\
Female & 126 & 21.69 & 13.44 & 126 & 7.53 & 9.46 & 126 & 35.47 & 8.70 \\
Bachelor & 120 & 20.45 & 11.63 & 120 & 6.48 & 8.00 & 120 & 35.57 & 8.87 \\
Master & 91 & 21.42 & 11.00 & 91 & 7.03 & 8.01 & 91 & 35.71 & 7.68 \\
PhD & 39 & 27.38 & 14.30 & 39 & 10.56 & 11.14 & 39 & 36.15 & 10.90 \\
Married & 179 & 20.00 & 11.37 & 179 & 6.61 & 8.37 & 179 & 35.29 & 8.90 \\
Single & 71 & 22.83 & 13.90 & 71 & 7.81 & 9.42 & 71 & 36.78 & 8.61 \\
\hline
\end{tabular}


The scores obtained from each gender are elaborated with references to the burnout dimensions as presented in Table 2. The mean score of the female teachers was higher than males in all three subscales of burnout (EE, DP and PA); totally the mean of the three subscales of burnout were moderate, hence, no high level of burnout was noticed. According to high score of master-holder teachers in comparison to bachelors, the burnout level of master-holders were more than bachelors but totally the exhaustion level was moderate in the both bachelors and master-holders in comparison to $\mathrm{PhD}$ level of educators which hold more higher level of burnout among teachers in this research. In addition, according to the results in Table 2, married and single teachers' burnout level was moderate, while mean score of the single teachers was higher than married ones.

Meanwhile, the one-way ANOVA test was used to study the effects of three demographic variables (gender, education level, and marital status) on teacher's burnout. The demographic variables regarded as independent variables, while the three burnout syndromes (emotional exhaustion, depersonalization and personal accomplishment) were taken as dependent variables. With reference to Table 3, the results of the gender and the levels of burnout indicated that there are no significant effects for two groups of gender across the three dimension levels of burnout $(\mathrm{F}=0.245, p>.05),(\mathrm{F}$ $=0.291, p>.05)$, and $(\mathrm{F}=0.664, p>.05)$. That is to say, there is not any significant difference between male and female teachers across the three syndromes of burnout. According to table 4, it seems that education level of the teachers significantly affect their burnout level in all three syndromes $(\mathrm{F}=.000, p<.05),(\mathrm{F}=.009, p<.05)$, and $(\mathrm{F}=.021, p<.05)$. This finding indicates that high educated teachers are at higher levels of burnout in dimensions of burnout. Teachers who are Master holders are at higher levels of burnout than Bachelor holders and $\mathrm{PhD}$ holders are at higher burnout levels than both Bachelor and Master holders. The same analytic tool was used to analyze marital status and the three dimensions of burnout. The results showed that teachers who are married have the same feelings with those who are single. On the other hand, Table 5 illustrates that there is no main effect of being married or single on the teachers' performance and their levels of burnout $(\mathrm{F}=0.097, p>.05),(\mathrm{F}=0.324, p>.05)$, and $(\mathrm{F}=0.225, p>.05)$.

Table 3. The ANOVA results on the effects of gender on burnout syndromes

\begin{tabular}{lllcccr}
\hline & Source & Sum of Squares & $\mathrm{df}$ & Mean Square & $\mathrm{F}$ & Sig. \\
\hline EE & Between Groups & 201.43 & 1 & 201.43 & 1.36 & .245 \\
& Within Groups & 36782.57 & 248 & 148.32 & & \\
\hline DP & Between Groups & 84.21 & 1 & 84.21 & 1.12 & .291 \\
& Within Groups & 18686.31 & 248 & 75.35 & & \\
\hline PA & Between Groups & 14.61 & 1 & 14.61 & .19 & .664 \\
& Within Groups & 19196.23 & 248 & 77.4 & & \\
\hline
\end{tabular}

Table 4. The ANOVA results on the effects of education level on burnout syndromes

\begin{tabular}{lllllll}
\hline & Source & Sum of Squares & df & Mean Square & F & Sig. \\
\hline EE & Between Groups & 2216.6 & 2 & 1108.35 & 2.201 & .000 \\
& Within Groups & 34767.31 & 144 & 47.635 & & \\
\hline DP & Between Groups & 612.6 & 2 & 306.03 & 4.163 & .009 \\
& Within Groups & 18158.46 & 247 & 73.52 & & \\
\hline PA & Between Groups & 9.86 & 2 & 4.93 & .063 & .021 \\
& Within Groups & 19200.97 & 247 & 77.74 & & \\
\hline
\end{tabular}

Table 5. The ANOVA results on the effects of marital status on burnout syndromes

\begin{tabular}{lllllll}
\hline & Source & Sum of Squares & df & Mean Square & F & Sig. \\
\hline EE & Between Groups & 409.03 & 1 & 409.03 & 2.77 & .097 \\
& Within Groups & 36574.97 & 248 & 147.48 & & \\
\hline DP & Between Groups & 73.49 & 1 & 73.49 & .98 & .324 \\
& Within Groups & 18.697 .02 & 248 & 75.39 & & \\
\hline
\end{tabular}




\section{Discussion}

The findings indicated that there is no significant difference between the male and female teachers in terms of their burnout level. This finding is in contrary to the findings of Maslach, Jackson, and Leiter (1996) along with Lau, Yuen, Chan (2005), Salami (2011), and Toker (2011) on service professionals including teachers which indicated that female staff had higher emotional exhaustion than their male colleagues. Abney (2009) has also reported that there is a significant difference between the two genders and the rate of burnout. Furthermore, the finding of this study is in line with that of Comber and Cormack's (2007). Comber and Cormack (2007) stated that gender did not affect the level of burnout among teachers. It was not possible to make more comparisons of the findings of this survey with other works in relation to the effect of educational level and burnout of teachers due to few researches done in access. However, a research conducted by F. Sezer (2012), he has reported that burnout level is high among high-educated teachers compared to low-educated teachers which is in line with the findings of this study. The present study has also shown that there is no significant difference between married and single teachers, and this finding is in accordance with the findings of Al-Qaryoti and Al-Khateeb (2006), who reported that being married or unmarried does not affect the level of burnout among Arab teachers. Similarly, the results of the research done by Bayram, Gursakal and Bilgel (2010) showed that marital status had no significant effect on burnout level of teachers.

In conclusion, this study was an attempt to investigate the effect of the three demographic variables (gender, education level, and marital status) on the burnout level of EFL teachers in northwest of Iran. By applying analysis of variance (ANOVA) and one-sample t-test, the mean scores for emotional exhaustion, depersonalization and personal accomplishment were not found to be high in due to gender and marital status. Hence, it was noticed that these two factors didn't affect the burnout level of the teachers, significantly. However, in terms of education level, the results showed that there is a significant difference among teachers with different levels of education and their burnout level; high educated teachers found to be at higher levels of burnout than low educated ones. For future studies, it is recommended to investigate the effects on the level of burnout among teachers with different ages, years of teaching experiences, salaries, or other demographic variables. Moreover, studies on the burnout level can be carried out in other areas; even in Iran or other countries to determine whether the setting affects the results.

\section{References}

Alavinia, P., \& Ahmadzadeh, T. (2012). Toward a reappraisal of the bonds between emotional intelligence and burnout. English Language Teaching Journal. 5(4), 37-50.

Al-Qaryoti, I., \& Al-Khateeb. F. (2006). Jamming visual culture. Literacy Learning in the Middle Years, 11(2), $15-21$.

Asghari, A. (2012). The effect of gender and marital status on burnout of English language teachers in Iran. Pertanika Journal of Social Sciences and Humanities, 20(3), 635-644.

Bayani, A. A., Bagheri, H., \& Bayani, A. (2013). Influence of gender, age, and years of teaching experience on burnout. Annals of Biological Research, 4(4), 239-243.

Bayram, N., Gürsakal, S., \& Bilgel, N. (2010). Burnout, vigor and job satisfaction among academic staff. European Journal of Social Sciences, 17(1).

Coulter, M. A., \& Abney, P. C. (2009). A study of burnout in international and country of origin teachers. International Review of Education, 55, 105-121.

Demir, Y. (2005). Level and correlates of burnout among orthopaedic nurses in Greece. Middle East Journal of Family Medicine, 3(3), 33-36.

Davis, J., \& Wilson, S. M. (2000). Principals' efforts to empower teachers: Effects on teacher motivation and job satisfaction and stress, Clearwing House, 73(6), 349-353.

Sezer, F. (2012). Examining of teacher burnout level in terms of some variables. International Online Journal of Educational Sciences, 4(3), 617-631.

Greenglass, E., Pantony, K. L. \& Burke, R. J. (1988). A gender-role perspective on rote conflict, work stress and social support. Journal of Social Behavior and Personality, 3, 317-328.

Jackson, S. E., Schwab, R. L., \& Schuler, R. S. (1986). Toward an understanding of the burnout phenomenon. Journal of Applied Psychology, 71(4), 630-640.

Landeche, P. (2009). The correlation between creativity and burnout in public school classroom teachers. Thesis submitted to the Graduate Faculty of the Louisiana State University and Agricultural and Mechanical College, Baton Rouge, LA. Retrieved from http://etd.lsu.edu/docs/available/etd-07082009090811/unrestricted/landechethesis.pdf.

Lance Hogan, J. A., \& McKnight, J. D. (2007). Depression, burnout, and perceptions of control in hospital nurses. Journal of Consulting and Clinical Psychology, 61, 147-155.

Lau, P. S., Yuen, M. T., \& Chan, R. M. (2005). Do demographic characteristics make a difference among Hong Kong secondary school teachers? Social Indicators Research, 71, 491-516.

Maslach, C., Jackson, S. E., \& Leiter, M. P. (1996). Maslach burnout inventory manual. Palo Alto, CA: Consulting Psychologists Press. 
Maslach, C., Schaufeli, W. B., \& Leiter, M. P. (2001). Job burnout. Annual Review of Psychology, 52, $397-422$.

Mukundan, J., \& Ahour, T. (2011). Burnout among female teachers in Malaysia. Journal of International Education Research, 7(3), 25-36.

Salami, S. O. (2011). Organizational role stress and burnout psychology essay. Asian Social Science, 7(50), $110-121$.

Sari, H. (2004). An analysis of burnout and job satisfaction among Turkish special school head-teachers and teachers, and the factors effecting their burnout and job satisfaction. Educational Studies, 30.

Shukla, A., \& Trivedi, T. (2008). Burnout in Indian teachers. Asian Pacific Studies Journal, 9(3), 320-334.

Tevfik, C. P. (2010). A study of the factors leading English teachers to burnout. H. U.Journal of Education, 38, $25-34$.

Toker, B. (2011). The influence of selected personality and workplace features on burnout among nurse academics. Doğuş Üniversitesi Dergisi, 12(1), 114-12.

Whitehead, A., Ryba, K., Driscoll, M. (2000). Burnout among New Zealand primary school teachers. New Zealand Journal of Psychology, 29(2), 52-61.

Yavuz, M. (2009). An investigation of burnout levels of teachers working in elementary and secondary educational institutions and their attitudes to classroom management. Educational Research and Reviews, 4(12), 642-649. 